\title{
A New Strategy for the Synthesis of Monomethylhydrazine Using the Raschig Process
}

\section{Duc Minh Le ${ }^{1,2}$, Anne-Julie Bougrine ${ }^{1,2}$, Olivier Duclos ${ }^{1,2}$, Véronique Pasquet ${ }^{1,2 *}$, Henri Delalu1,2}

${ }^{1}$ Laboratoire Hydrazines et Composés Energétiques Polyazotés, Université Claude Bernard Lyon 1, Villeurbanne, France ${ }^{2} \mathrm{UCBL} / \mathrm{CNRS} / \mathrm{CNES} /$ ArianeGroup, Bâtiment Raulin, Villeurbanne, France

Email: *veronique.pasquet@univ-lyon1.fr

How to cite this paper: Le, D.M., Bougrine, A.-J., Duclos, O., Pasquet, V. and Delalu, H. (2021) A New Strategy for the Synthesis of Monomethylhydrazine Using the Raschig Process. Advances in Chemical Engineering and Science, 11, 228-238. https://doi.org/10.4236/aces.2021.113014

Received: March 9, 2021

Accepted: June 18, 2021

Published: June 21, 2021

Copyright (c) 2021 by author(s) and Scientific Research Publishing Inc. This work is licensed under the Creative Commons Attribution International License (CC BY 4.0).

http://creativecommons.org/licenses/by/4.0/

\begin{abstract}
A new strategy for the development of monomethylhydrazine (MMH) using the Raschig process is discussed in this publication. The determination of optimal conditions for the synthesis of MMH required the development of a kinetic model. In order to validate the results of the calculation, a device for synthesis under pressure (13 bar) by direct injection of the stoichiometric monochloramine, synthesized using microreactor technology, into monomethylamine (MMA) was developed. The experimental data, in accordance with the theoretical results of the kinetic model, make it possible to establish a new process for the synthesis of monomethylhydrazine.
\end{abstract}

\section{Keywords}

Synthesis, Raschig, Monomethylhydrazine, Kinetic Model

\section{Introduction}

The objective of this work is to develop a new strategy for the preparation of monomethylhydrazine (MMH) by intensification of the Raschig process, using microreactor technology. This compound is today a molecule with great potential in the field of propulsion, the pharmaceutical industry and agrochemistry. In the first part of this study already published [1], it was concluded that, given the instability of stoichiometric monochloramine solutions from $36^{\circ} \mathrm{C}$ and in order to control heat exchanges, the microreactor technology will be the best choice to avoid any sudden degradation leading to the formation of nitrogen chloride $\mathrm{NCl}_{3}$. In the second part [2], the optimal conditions for the synthesis of stoichi- 
ometric monochloramine were established, using this microreactor technology.

This third part concerns the synthesis of monomethylhydrazine (MMH) using the monochloramine synthesized via the microreactor technology. As a first step, it was necessary to establish the different reactions involved in the process. A kinetic model was then formulated. The influence of the monomethylamine/monochloramine initial molar ratio on $\mathrm{MMH}$ yield was determined by integrating the differential equation system of this model. Finally, experimental tests of the synthesis of $\mathrm{MMH}$ under pressure were carried out.

\section{Experimental Part}

\subsection{Specific Device}

The experiments were carried out in a specific device, the schema of which is presented in Figure 1. It allows the direct injection of a monochloramine solution prepared under stoichiometric conditions into anhydrous MMA. It is composed of a 316 stainless steel reactor with a capacity of $180 \mathrm{~mL}$ that can withstand a maximum pressure of $200 \mathrm{bar}$ at $250^{\circ} \mathrm{C}$. The injection is carried out using an Optos $2 \mathrm{HM}$ dosing pump (max flow rate: $40 \mathrm{~mL} \cdot \mathrm{min}^{-1}$; Pmax: $100 \mathrm{bar}$ ). The reactor is heated by a $500 \mathrm{~W}$ electric furnace insulated under a collar-shaped stainless steel jacket. It is fixed by flanges allowing it to slide easily along the reactor. The temperature of the reaction medium is maintained at the set temperature by means of a PID-type controller that supplies the furnace via a 25 Ampere solid-state relay. The device is completed by a mechanical agitator to ensure a homogeneous synthesis solution, a bottle of anhydrous MMA and a tank for the chloramine solution, without forgetting a thermometer, a manometer, a balance and a dosing pump.

\subsection{Experimental Protocol}

Before each experiment, the device is dried with nitrogen and then sealed. The tank containing the pre-weighed anhydrous MMA is then connected to the

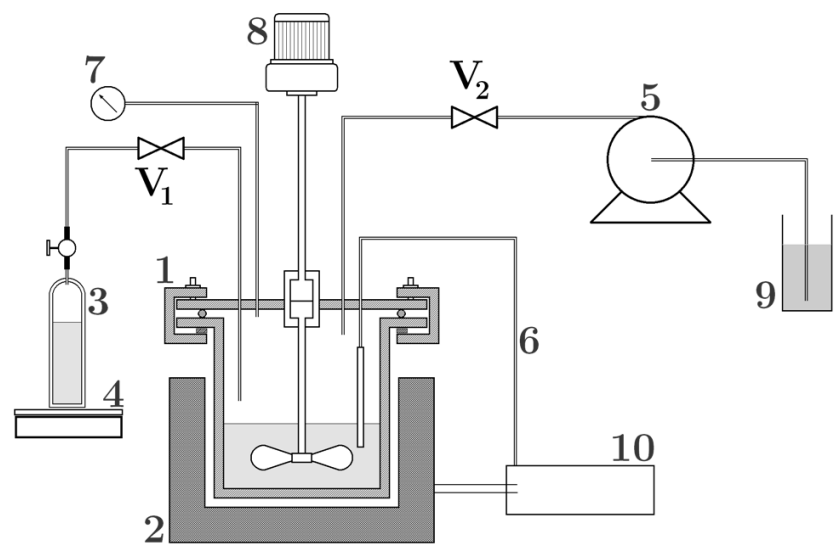

Figure 1. Diagram of the experimental device. (1) Stainless steel reactor; (2) electric furnace; (3) bottle of anhydrous MMA; (4) balance; (5) dosing pump; (6) thermometer; (7) manometer; (8) mechanical agitator; (9) tank for the chloramine solution. 
reactor at valve V1 (Figure 1). The transfer of the anhydrous MMA is carried out by cryogenic trapping after quenching the autoclave in a Dewar filled with liquid air. When the temperature reaches $-50^{\circ} \mathrm{C}$ to $-60^{\circ} \mathrm{C}$, the vaporized MMA is introduced slowly at a rate of $1 \mathrm{~g} \cdot \mathrm{min}^{-1}$. The variation of the apparent mass of the MMA tank allows control of the speed of introduction as well as the quantity introduced. At the end of the operation, the MMA container is disconnected from the device, dried and weighed again to determine the exact amount of reagent introduced.

After removal of the cold source from the central reactor, the reactor is placed in the electric furnace and the temperature is set at $70^{\circ} \mathrm{C}$. When thermal equilibrium is reached, the pressure in the reactor is 13.3 bar (saturated vapor pressure of MMA at $70^{\circ} \mathrm{C}$ ). The stirring system is then switched on. The freshly prepared and alkalized chloramine solution is then introduced into the reactor under pressure using the dosing pump. Agitation is maintained until the reactions are completed.

At the end of the synthesis, the reactor is cooled to room temperature after extraction from the furnace. The synthesis solution is then analyzed by HPLC and UV-Visible.

\subsection{Analytical Methods}

UV spectrometry

The spectrophotometer used was an Agilent Cary 100 dual-beam spectrophotometer equipped with the Cary WinUV data acquisition system. It allows a repetitive scanning of spectra between $180 \mathrm{~nm}$ and $900 \mathrm{~nm}$, programmable as a function of time, and measurements of optical density or its derivatives at a given wavelength. Measurements were made with Hellma ${ }^{\circledR}$ brand Suprasil ${ }^{\circledR}$ quartz cells, model 100-QS with a $10 \mathrm{~mm}$ optical path, to ensure optimal transmission of UV signals.

As MMH is a molecule transparent to ultraviolet light, its dosage is carried out indirectly, based on the quantitative formation of formaldehyde monomethylhydrazone (FMMH), by condensation of $\mathrm{MMH}$ on formaldehyde. Hydrazine $\mathrm{N}_{2} \mathrm{H}_{4}$ is also indirectly dosed. Its concentration is determined on the basis of the formation of a yellow azine by reaction of $\mathrm{N}_{2} \mathrm{H}_{4}$ with paradimethylaminobenzaldehyde (PDAB) [3].

HPLC

The device used is an Agilent HP 1100 chromatograph combined with a diode array UV detector. The data acquisition system is managed by the ChemStation HP 3365 software. This technique has been used for the analysis of MMH and FMMH in synthetic solutions. The separator column is ZORBAX XDB-CN with dimensions $250 \mathrm{~mm} \times 4.6 \mathrm{~mm}$ and a particle size of $5 \mu \mathrm{m}$. This column is equipped with a pre-column for basic injections. The mobile phase is $\mathrm{H}_{2} \mathrm{O}$ in isocratic regime. The conditions are as follow: flow rate of $1 \mathrm{~mL} \cdot \mathrm{min}^{-1}$, injected volume of $20 \mu \mathrm{L}, \mathrm{UV}$ detector at $\lambda=230 \mathrm{~nm}$. 


\section{Chemical products.}

The permuted water used is city water purified by passing over an ion exchange resin. The inorganic salts and organic solvents used are of commercial purity (minimum 98\%) and are supplied by Acros Organics, Merck and Sigma-Aldrich. They were used without prior purification unless otherwise indicated. Aqueous solutions of sodium hypochlorite $\mathrm{NaOCl}$ and sodium hydroxide are supplied by Arkema (Jarrie Plant, Grenoble, France). The aqueous solution, measuring approximately 48 chlorometric degrees $\left(2.4 \mathrm{~mol} \cdot \mathrm{L}^{-1}\right)$, is stored at $5{ }^{\circ} \mathrm{C}$ and systematically titrated before use. Anhydrous MMA is more than $98 \%$ pure and is supplied by Sigma-Aldrich.

\section{Results and Discussion}

\subsection{Analysis of the Different Reactions Involved in the Process}

\subsubsection{Monomethylhydrazine Formation}

The formation of MMH corresponds to the general scheme of the Raschig process:

$$
\begin{gathered}
\mathrm{NH}_{2} \mathrm{Cl}+\mathrm{RR}^{\prime} \mathrm{NH}+\mathrm{OH}^{-} \stackrel{k}{\longrightarrow} \mathrm{RR}^{\prime} \mathrm{N}-\mathrm{NH}_{2}+\mathrm{Cl}^{-}+\mathrm{H}_{2} \mathrm{O} \\
\mathrm{NH}_{2} \mathrm{Cl}+\mathrm{CH}_{3} \mathrm{NH}_{2}+\mathrm{OH}^{-} \stackrel{k_{1}}{\longrightarrow} \mathrm{CH}_{3} \mathrm{NH}-\mathrm{NH}_{2}+\mathrm{Cl}^{-}+\mathrm{H}_{2} \mathrm{O}
\end{gathered}
$$

The constant $k_{1}$ was determined in the laboratory from the rate of $\mathrm{MMH}$ formation at the time $t=0$. It is written as a function of the $\mathrm{NH}_{2} \mathrm{Cl}$ (monochloramine) and $\mathrm{CH}_{3} \mathrm{NH}_{2}$ (MMA) initial molar concentrations [4]:

$$
\left(\frac{\mathrm{d}\left[\mathrm{CH}_{3} \mathrm{NHNH}_{2}\right]}{\mathrm{d} t}\right)_{t=0}=k_{1} \cdot\left[\mathrm{NH}_{2} \mathrm{Cl}\right]_{0} \cdot\left[\mathrm{CH}_{3} \mathrm{NH}_{2}\right]_{0}
$$

According to the author, the formation of MMH corresponds to the superposition of a pH-independent step, which is carried out according to a nucleophilic substitution mechanism of the SN2 type, and a step related to the weak acidic character of $\mathrm{NH}_{2} \mathrm{Cl}$, which means $\mathrm{pH}$ dependence.

Consequently, the evolution of the rate constant as a function of $\mathrm{pH}$ and temperature is translated by the following relationship:

$$
k_{1}=\lambda_{1}+\lambda_{1}^{\prime} \cdot \frac{1}{\left[\mathrm{H}^{+}\right]}
$$

where $\lambda_{1}$ and $\lambda_{2}$ are empirical constants for both phenomena. They obey the law of Arrhenius and can be written in the form:

$$
\begin{gathered}
\lambda_{1}=A_{1} \cdot \mathrm{e}^{-\frac{E_{1}}{R T}}, \quad E_{1}=63.2 \mathrm{~kJ} \cdot \mathrm{mol}^{-1}, \quad A_{1}=4.84 \times 10^{8} \mathrm{~L} \cdot \mathrm{mol}^{-1} \cdot \mathrm{s}^{-1} \\
\lambda_{1}^{\prime}=A_{1}^{\prime} \cdot \mathrm{e}^{-\frac{E_{1}^{\prime}}{R T}}, \quad E_{1}^{\prime}=124.7 \mathrm{~kJ} \cdot \mathrm{mol}^{-1}, \quad A_{1}^{\prime}=2.01 \times 10^{5} \mathrm{~s}^{-1}
\end{gathered}
$$

\subsection{2. $\mathrm{NH}_{2} \mathrm{Cl} / \mathrm{MMH}$ Reaction}

The kinetics of the monochloramine oxidation reaction of MMH was studied as a function of temperature and $\mathrm{pH}$. The main product of the reaction is formaldehyde monomethylhydrazone (FMMH) [4]. 


$$
\begin{aligned}
& \mathrm{CH}_{3} \mathrm{NH}-\mathrm{NH}_{2}+\mathrm{NH}_{2} \mathrm{Cl} \stackrel{k_{2}}{\longrightarrow}[\text { intermediate }] \\
& \stackrel{\text { fast }}{\longrightarrow} \cdots+\frac{1}{2} \mathrm{CH}_{3} \mathrm{NH}-\mathrm{N}=\mathrm{CH}_{2}+\cdots
\end{aligned}
$$

Despite the complexity of the reaction, for the experimental conditions used, the stoichiometry is close to 1 (experimental value: 0.93 ), partial orders are equal to unity and the main product of the reaction is the FMMH. Limited quantities of methanol $\left(\mathrm{CH}_{3} \mathrm{OH}\right)$ and methyl-chloride $\left(\mathrm{CH}_{3} \mathrm{Cl}\right)$ are also produced.

The reaction appears to be the combination of two reaction mechanisms, one of which is the seat of an acid catalysis phenomenon:

$$
k_{2}=\lambda_{2}+\lambda_{2}^{\prime} \cdot\left[\mathrm{H}^{+}\right]
$$

The numerical values of the constants $\lambda_{2}$ and $\lambda_{2}^{\prime}$ as a function of temperature are as follows:

$$
\begin{aligned}
& \lambda_{2}=A_{2} \cdot \mathrm{e}^{-\frac{E_{2}}{R T}}, \quad E_{2}=45.0 \mathrm{~kJ} \cdot \mathrm{mol}^{-1}, A_{2}=1.60 \times 10^{6} \mathrm{~L} \cdot \mathrm{mol}^{-1} \cdot \mathrm{s}^{-1} \\
& \lambda_{2}^{\prime}=A_{2}^{\prime} \cdot \mathrm{e}^{-\frac{E_{2}^{\prime}}{R T}}, \quad E_{2}^{\prime}=36.3 \mathrm{~kJ} \cdot \mathrm{mol}^{-1}, A_{2}^{\prime}=9.74 \times 10^{16} \mathrm{~L}^{2} \cdot \mathrm{mol}^{-2} \cdot \mathrm{s}^{-1}
\end{aligned}
$$

These data allow to describe in a satisfying way the first moments of the $\mathrm{MMH}$ synthesis but the gap between calculated and experimental results increases with $\mathrm{pH}$ and temperature. This behaviour had already been reported by Ferriol et al. [4]. Taking up their experimental results, Giudice [5] proposed the following empirical expression for the constant $k_{2}$ :

$$
\begin{aligned}
k_{2}= & 1.175 \times 10^{18} \exp \left(-\frac{13575}{T}\right)+\frac{1.79 \times 10^{19}}{10^{-18}}\left[\mathrm{H}^{+}\right] \exp \left(-\frac{11575}{T}\right) \\
& +\frac{9.2 \times 10^{14}}{\left[\mathrm{H}^{+}\right]} 10^{-7.85} \exp \left(-\frac{8400}{T}\right)
\end{aligned}
$$

\subsubsection{Halogen Exchange Reaction between Monochloramine and Monomethylamine}

A laboratory study [6] showed that the reaction between chloramine and an amine also led to the formation of an alkylchloramine. This transfer reaction leads to a state of equilibrium.

$$
\mathrm{CH}_{3} \mathrm{NH}_{2}+\mathrm{NH}_{2} \mathrm{Cl} \stackrel{k_{3}}{\rightleftarrows} \mathrm{CH}_{3} \mathrm{NHCl}+\mathrm{NH}_{3}
$$

In a basic medium, the reaction for the formation of methylchloramine is of the first order compared to $\mathrm{NH}_{2} \mathrm{Cl}$ and $\mathrm{CH}_{3} \mathrm{NH}_{2}$. It is catalysed by the acidic species which determine the $\mathrm{pH}$ of the medium. The rate constant $k_{3}$, in this case, is expressed as:

$$
k_{3}=\left(\lambda_{30}+\lambda_{31} \cdot a_{\mathrm{H}^{+}}+\lambda_{32} \cdot \frac{a_{\mathrm{H}^{+}} \cdot\left[\mathrm{NH}_{3}\right]_{T}}{K_{a}^{\mathrm{NH}_{4}^{+}} \cdot \frac{f_{\mathrm{NH}_{4}^{+}}}{f_{\mathrm{NH}_{3}}}+a_{\mathrm{H}^{+}}}\right) \cdot\left(\frac{K_{a}^{\mathrm{CH}_{3} \mathrm{NH}_{3}^{+}} \cdot \frac{f_{\mathrm{CH}_{3} \mathrm{NH}_{3}^{+}}}{f_{\mathrm{CH}_{3} \mathrm{NH}_{2}}}}{K_{a}^{\mathrm{CH}_{3} \mathrm{NH}_{3}^{+}} \cdot \frac{f_{\mathrm{CH}_{3} \mathrm{NH}_{3}^{+}}}{f_{\mathrm{CH}_{3} \mathrm{NH}_{2}}}+a_{\mathrm{H}^{+}}}\right)
$$

with: 
- $f_{i}$ coefficient of activity of species $i$;

- $a_{i}$ activity of species $i$ as defined by:

$$
a_{i}=f_{i} \cdot \frac{[i]}{C_{0}}
$$

The term $C_{0}$ is the reference concentration. It is conventionally equal to 1 $\mathrm{mol} \cdot \mathrm{L}^{-1}$.

- $K_{a i}$ acidity constant of the species $i$;

The experimental values of $\lambda_{3 i}(i=0,1,2)$ at $25^{\circ} \mathrm{C}$ are as follows:

$$
\begin{aligned}
& \lambda_{30}=8.3 \times 10^{-4} \mathrm{~L} \cdot \mathrm{mol}^{-1} \cdot \mathrm{s}^{-1} \\
& \lambda_{31}=7.5 \times 10^{9} \mathrm{~L}^{2} \cdot \mathrm{mol}^{-2} \cdot \mathrm{s}^{-1} \\
& \lambda_{32}=0.74 \mathrm{~L}^{2} \cdot \mathrm{mol}^{-2} \cdot \mathrm{s}^{-1} .
\end{aligned}
$$

In very basic medium $(\mathrm{pH}>13)$, the constant $k_{3}$ follows the Arrhenius law with an activation energy $E_{3}$ of $59.8 \mathrm{~kJ} \cdot \mathrm{mol}^{-1}$ and a pre-exponential factor $A_{3}$ of $6.25 \times 10^{7} \mathrm{~L} \cdot \mathrm{mol}^{-1} \cdot \mathrm{s}^{-1}[6]$.

$$
k_{3}=A_{3} \cdot \mathrm{e}^{-\frac{E_{3}}{R T}}, \quad E_{3}=59.8 \mathrm{~kJ} \cdot \mathrm{mol}^{-1}, \quad A_{3}=6.25 \times 10^{7} \mathrm{~L} \cdot \mathrm{mol}^{-1} \cdot \mathrm{s}^{-1}
$$

\subsubsection{Formation and Degradation Reactions of Hydrazine $\mathrm{N}_{2} \mathrm{H}_{4}$}

The reactions involved in the formation and degradation of hydrazine $\mathrm{N}_{2} \mathrm{H}_{4}$ have been the subject of many long-standing studies [7] [8]. The results present some analogies to MMH that should be noted.

$$
\begin{gathered}
\mathrm{NH}_{2} \mathrm{Cl}+\mathrm{NH}_{3}+\mathrm{OH}^{-} \rightarrow \mathrm{N}_{2} \mathrm{H}_{4}+\mathrm{Cl}^{-}+\mathrm{H}_{2} \mathrm{O} \\
2 \mathrm{NH}_{2} \mathrm{Cl}+\mathrm{N}_{2} \mathrm{H}_{4} \rightarrow 2 \mathrm{NH}_{4} \mathrm{Cl}+\mathrm{N}_{2}
\end{gathered}
$$

The overall reaction of formation corresponds to two mechanisms, one independent of $\mathrm{pH}$ and the other catalyzed by $\mathrm{OH}^{-}$ions.

The formation rate constant $k_{4}$ for hydrazine $\mathrm{N}_{2} \mathrm{H}_{4}$ is as follows:

$$
k_{4}=\lambda_{4}+\lambda_{4}^{\prime} \cdot \frac{1}{\left[\mathrm{H}^{+}\right]}
$$

The constants $\lambda_{4}$ and $\lambda_{4}^{\prime}$ are expressed by the relationships [8]:

$$
\begin{gathered}
\lambda_{4}=A_{4} \cdot \mathrm{e}^{-\frac{E_{4}}{R T}}, \quad E_{4}=74.0 \mathrm{~kJ} \cdot \mathrm{mol}^{-1}, \quad A_{4}=1.05 \times 10^{9} \mathrm{~L} \cdot \mathrm{mol}^{-1} \cdot \mathrm{s}^{-1} \\
\lambda_{4}^{\prime}=A_{4}^{\prime} \cdot \mathrm{e}^{-\frac{E_{4}^{\prime}}{R T}}, \quad E_{4}^{\prime}=68.1 \mathrm{~kJ} \cdot \mathrm{mol}^{-1}, \quad A_{4}^{\prime}=5.6 \times 10^{7} \mathrm{~s}^{-1}
\end{gathered}
$$

The overall oxidation reaction of hydrazine $\mathrm{N}_{2} \mathrm{H}_{4}$ by monochloramine is also the result of two mechanisms, one of which is $\mathrm{pH}$-independent, the second catalyzed by $\mathrm{H}^{+}$ions. Based on studies carried out in our laboratory several years ago, the following expression for the constant $k_{5}$ was obtained:

$$
k_{5}=\left(5 \times 10^{-3}+1.95 \times 10^{10}\left[\mathrm{H}^{+}\right]\right) \exp \left[\frac{15100}{R}\left(\frac{1}{298.4}-\frac{1}{T}\right)\right]
$$

\subsubsection{Decomposition of Monochloramine in Basic Medium}

The decomposition of monochloramine in basic medium was studied by Anbar 
et al. [9]. According to these authors, the process begins with a step of reaction hydrolysis:

$$
\mathrm{NH}_{2} \mathrm{Cl}+\mathrm{OH}^{-} \rightarrow \mathrm{NH}_{2} \mathrm{OH}+\mathrm{Cl}^{-}
$$

The hydroxylamine formed reacts instantaneously with $\mathrm{NH}_{2} \mathrm{Cl}$ :

$$
\begin{gathered}
2 \mathrm{NH}_{2} \mathrm{Cl}+2 \mathrm{NH}_{2} \mathrm{OH}+2 \mathrm{OH}^{-} \rightarrow \mathrm{N}_{2} \mathrm{O}+2 \mathrm{NH}_{3}+3 \mathrm{H}_{2} \mathrm{O}+2 \mathrm{Cl}^{-} \\
\mathrm{NH}_{2} \mathrm{Cl}+2 \mathrm{NH}_{2} \mathrm{OH}+\mathrm{OH}^{-} \rightarrow \mathrm{N}_{2}+\mathrm{NH}_{3}+3 \mathrm{H}_{2} \mathrm{O}+\mathrm{Cl}^{-}
\end{gathered}
$$

The hydrolysis reaction could never be demonstrated with certitude because, as soon as it is formed, hydroxylamine is spontaneously consumed by the monochloramine present in the medium. However, product identification shows $\mathrm{N}_{2}$, $\mathrm{N}_{2} \mathrm{O}, \mathrm{NH}_{3}$ as the majority compounds [10].

Modelling of monochloramine hydrolysis in basic medium is complex and at $\mathrm{pH}$ above 11, the reaction kinetics are of order 1 with respect to $\mathrm{NH}_{2} \mathrm{Cl}$ and $\mathrm{OH}^{-}$ ions [5] [9] [10]. The rate constant is expressed as follows [5]:

$$
k_{0}=\frac{2.55 \times 10^{9}}{\left[\mathrm{H}^{+}\right]} \exp \left(-\frac{19200}{T}\right)
$$

\subsection{Formulation of the Kinetic Model}

Based on the above analysis, the main reactions that affect the yield during the synthesis of $\mathrm{MMH}$ by the monochloramine route are as follows:

$$
\begin{aligned}
& \mathrm{NH}_{2} \mathrm{Cl} \underset{\mathrm{OH}^{-}}{\stackrel{k_{0}}{\longrightarrow}} \mathrm{NH}_{3}+\text { degradation products } \\
& \mathrm{NH}_{2} \mathrm{Cl}+\mathrm{CH}_{3} \mathrm{NH}_{2} \underset{\mathrm{OH}^{-}}{\stackrel{k_{1}}{\longrightarrow}} \mathrm{CH}_{3} \mathrm{NHNH}_{2}+\mathrm{HCl} \\
& \mathrm{HCl}+\mathrm{NaOH} \stackrel{\text { fast }}{\longrightarrow} \mathrm{NaCl}+\mathrm{H}_{2} \mathrm{O} \\
& \mathrm{NH}_{2} \mathrm{Cl}+\mathrm{CH}_{3} \mathrm{NHNH}_{2} \underset{\mathrm{OH}^{-}}{\stackrel{k_{2}}{\longrightarrow}} \frac{1}{2} \mathrm{CH}_{3} \mathrm{NHN}=\mathrm{CH}_{2}+\mathrm{NH}_{3}+\cdots \\
& \mathrm{NH}_{2} \mathrm{Cl}+\mathrm{CH}_{3} \underset{\mathrm{OH}^{-}}{\stackrel{k_{3}}{\longrightarrow}} \mathrm{NH}_{2} \mathrm{NH}_{3}+\mathrm{CH}_{3} \mathrm{NHCl} \\
& \mathrm{NH}_{2} \mathrm{Cl}+\mathrm{NH}_{3} \underset{\mathrm{OH}^{-}}{\stackrel{k_{4}}{\longrightarrow}} \mathrm{N}_{2} \mathrm{H}_{4}+\mathrm{HCl} \\
& \mathrm{HCl}+\mathrm{NaOH} \stackrel{\text { fast }}{\longrightarrow} \mathrm{NaCl}+\mathrm{H}_{2} \mathrm{O} \\
& 2 \mathrm{NH}_{2} \mathrm{Cl}+\mathrm{N}_{2} \mathrm{H}_{4} \underset{\mathrm{OH}^{-}}{\stackrel{k_{5}}{\longrightarrow}} 2 \mathrm{NH}_{4} \mathrm{Cl}+\mathrm{N}_{2} \\
& \mathrm{NH}_{4} \mathrm{Cl}+\mathrm{NaOH} \stackrel{\text { fast }}{\longrightarrow} \mathrm{NaCl}+\mathrm{NH}_{3}+\mathrm{H}_{2} \mathrm{O}
\end{aligned}
$$

The knowledge of the instantaneous concentrations of the main entities and the predictive calculation of the yield as a function of the reagent concentrations, $\mathrm{pH}$ and temperature are linked to the resolution of the system of differential equations defined by the laws of reaction rates. By designating $x, a, u_{1}, s, z, u_{2}, b$ and $y$ respectively the concentrations of monochloramine, MMA, MMH, FMMH, $\mathrm{NH}_{3}, \mathrm{~N}_{2} \mathrm{H}_{4}, \mathrm{OH}^{-}, \mathrm{NaCl}$, the system is written:

$$
\frac{\mathrm{d}}{\mathrm{d} t} x(t)=-\left[k_{0}+k_{1} \cdot a(t)+k_{2} \cdot u_{1}(t)+k_{3} \cdot a(t)+k_{4} \cdot s(t)+k_{5} \cdot u_{2}(t)\right] \cdot x(t)
$$




$$
\begin{gathered}
\frac{\mathrm{d}}{\mathrm{d} t} a(t)=-\left(k_{1}+k_{3}\right) \cdot a(t) \cdot x(t) \\
\frac{\mathrm{d}}{\mathrm{d} t} u_{1}(t)=k_{1} \cdot a(t) \cdot x(t)-k_{2} \cdot u_{1}(t) \cdot x(t) \\
\frac{\mathrm{d}}{\mathrm{d} t} s(t)=\frac{1}{2} k_{2} \cdot u_{1}(t) \cdot x(t) \\
\frac{\mathrm{d}}{\mathrm{d} t} z(t)=k_{2} \cdot x(t) \cdot u_{1}(t)+k_{3} \cdot a(t) \cdot x(t)-k_{4} \cdot z(t) \cdot x(t)+2 k_{5} \cdot u_{2}(t) \cdot x(t) \\
\frac{\mathrm{d}}{\mathrm{d} t} u_{2}(t)=k_{4} \cdot z(t) \cdot x(t)-k_{5} \cdot u_{2}(t) \cdot x(t) \\
\frac{\mathrm{d}}{\mathrm{d} t} b(t)=-k_{1} \cdot a(t) \cdot x(t)-k_{2} \cdot u_{1}(t) \cdot x(t)-k_{4} \cdot z(t) \cdot x(t)-2 k_{5} \cdot u_{2}(t) \cdot x(t) \\
\frac{\mathrm{d}}{\mathrm{d} t} y(t)=k_{1} \cdot a(t) \cdot x(t)+k_{2} \cdot u_{1}(t) \cdot x(t)+k_{4} \cdot z(t) \cdot x(t)+2 k_{5} \cdot u_{2}(t) \cdot x(t)
\end{gathered}
$$

with initial conditions (at $t=0$ ):

$$
\begin{array}{ll}
x(0)=x_{0}, & a(0)=a_{0} \\
u_{1}(0)=0, & s(0)=0 \\
z(0)=z_{0}, & u_{2}(0)=0 \\
b(0)=b_{0}, & y(0)=y_{0}
\end{array}
$$

It has been solved numerically by the method of Runge-Kutta of the $7^{\text {th }}$ order. This method was chosen because it does not require [11] any additional functions, any further differentiation, any additional initial value.

In this work, the calculations were performed using the Maple computer algebra software.

\subsection{Integration of the System of Differential Equations}

The system was integrated according to the $[\mathrm{MMA}]_{0} /\left[\mathrm{NH}_{2} \mathrm{Cl}\right]_{0}$ ratio and $\mathrm{pH}$.

\subsection{Influence of the Ratio $[\mathrm{MMA}]_{0} /\left[\mathrm{NH}_{2} \mathrm{Cl}\right]_{0}$}

Figure 2 shows the $\mathrm{MMH}$ yield at $70^{\circ} \mathrm{C}$ as a function of the ratio of initial concentrations and various final $\mathrm{NaOH}$ concentrations.

Figure 2 shows that the yield increases with the ratio of initial concentrations $[\mathrm{MMA}]_{0} /\left[\mathrm{NH}_{2} \mathrm{Cl}\right]_{0}$. This phenomenon is related to an increase in the rate of $\mathrm{MMH}$ formation at the expense of the oxidation reaction. For a ratio of 10 and a final $\mathrm{NaOH}$ concentration of $0.7 \mathrm{~mol} \cdot \mathrm{L}^{-1}$, it is not possible to exceed a yield of $71 \%$. It is therefore necessary to use a ratio close to 20 and a final $\mathrm{NaOH}$ concentration higher than $0.7 \mathrm{~mol} \cdot \mathrm{L}^{-1}$.

\subsection{Synthesis of MMH under Pressure}

Experiments were carried out using stoichiometric monochloramine to control the model and verify the absence of hydrazine $\mathrm{N}_{2} \mathrm{H}_{4}$ in the crude synthetis solutions. 


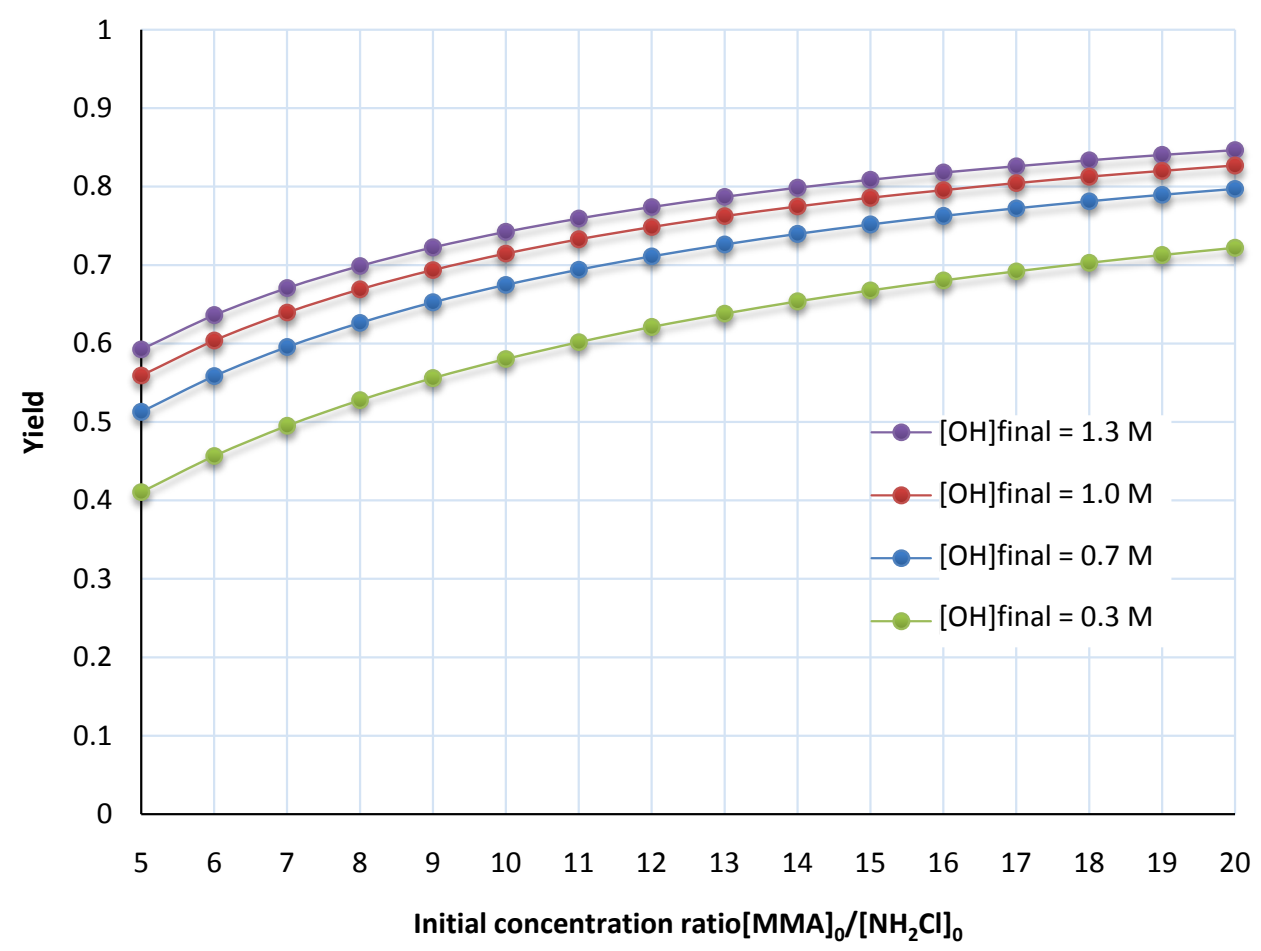

Figure 2. Influence of the $[\mathrm{MMA}]_{0} /\left[\mathrm{NH}_{2} \mathrm{Cl}\right]_{0}$ ratio on the $\mathrm{MMH}$ synthesis yield at different values of the final sodium hydroxide concentration $\left(T=70^{\circ} \mathrm{C}\right)$.

The synthesis of $\mathrm{MMH}$ in discontinuous and pressurized form required the installation of a specific device. It allows the direct injection of a monochloramine solution prepared under stoichiometric conditions into anhydrous MMA. Its principle diagram is described in experimental part.

\section{Results}

The kinetic model described above has been integrated to calculate the theoretical MMH and FMMH yield and the final $[\mathrm{MMH}] /\left[\mathrm{N}_{2} \mathrm{H}_{4}\right]$ ratio. The integration of the system of differential equations was performed using the Maple computer algebra software.

We observe that the computed results are in fairly good agreement with the experimental results since the difference between the calculated and experimental yields is of $\pm 5 \%$ as seen in Table 1 . The best result was obtained for an initial ratio of $[\mathrm{MMA}]_{0} /\left[\mathrm{NH}_{2} \mathrm{Cl}\right]_{0}$ equal to about 20 and a final concentration of $\mathrm{NaOH}$ equal to 0.7 .

Concerning the $\mathrm{N}_{2} \mathrm{H}_{4}$ by-product, the theoretical results indicate a [MMH]/ $\left[\mathrm{N}_{2} \mathrm{H}_{4}\right]$ ratio lower than 11,000 . The PDAB UV measurements do not show any trace of hydrazine (presence below the detection limit).

All the results of the synthesis and extraction segments allowed the development of a simplified schematic diagram presented in Figure 3. It corresponds to the objectives set, namely, the use of stoichiometric chloramine and a reduction in unit operations. 
Table 1. Modeled and experimental results of the synthesis of MMH under pressure from anhydrous MMA $\left(T=70^{\circ} \mathrm{C}\right) . Y=$ yield.

\begin{tabular}{|c|c|c|c|c|c|}
\hline Exp. $\mathrm{N}^{\circ}$ & $m_{\mathrm{MMA}}$ & $V_{\mathrm{NH}_{2} \mathrm{Cl}}$ & $C_{\mathrm{NH}_{2} \mathrm{Cl}}$ & $C_{\mathrm{NaOH}}$ final & {$[\mathrm{MMA}]_{0} /\left[\mathrm{NH}_{2} \mathrm{Cl}\right]_{0}$} \\
\hline & g & $\mathrm{mL}$ & $\mathrm{mol} \cdot \mathrm{L}^{-1}$ & $\mathrm{~mol} \cdot \mathrm{L}^{-1}$ & $(\mathrm{~N} / \mathrm{C})$ \\
\hline 1 & 20.23 & 60.3 & 1.07 & 0.7 & 10.1 \\
\hline 2 & 21.32 & 65.7 & 1.05 & 0.7 & 10.0 \\
\hline 3 & 30.10 & 80.1 & 1.06 & 0.3 & 11.4 \\
\hline 4 & 35.21 & 51.2 & 1.07 & 0.3 & 20.7 \\
\hline 5 & 40.32 & 61.2 & 1.05 & 0.7 & 20.2 \\
\hline 6 & 33.77 & 51.2 & 1.06 & 0.7 & 20.1 \\
\hline \multirow[t]{2}{*}{ Exp. $\mathrm{N}^{\circ}$} & $\begin{array}{c}Y_{\mathrm{MMH}} \\
\text { modeled }\end{array}$ & $\begin{array}{c}Y_{\mathrm{FMMH}} \\
\text { modeled }\end{array}$ & $\begin{array}{c}Y_{\mathrm{MMH}} \\
\text { experimental }\end{array}$ & $\begin{array}{c}Y_{\mathrm{FMMH}} \\
\text { experimental }\end{array}$ & {$[\mathrm{MMH}] /\left[\mathrm{N}_{2} \mathrm{H}_{4}\right]$ modeled } \\
\hline & $\%$ & $\%$ & $\%$ & $\%$ & \\
\hline 1 & 68.9 & 7.2 & 65.3 & 9.1 & 5100 \\
\hline 2 & 67.9 & 7.4 & 62.2 & 8.2 & 4853 \\
\hline 3 & 61.1 & 8.9 & 57.3 & 10.0 & 4302 \\
\hline 4 & 74.8 & 5.5 & 70.1 & 8.0 & 9088 \\
\hline 5 & 80.9 & 4.2 & 82.3 & 5.3 & 11,070 \\
\hline 6 & 79.6 & 4.5 & 75.1 & 5.5 & 10,537 \\
\hline
\end{tabular}

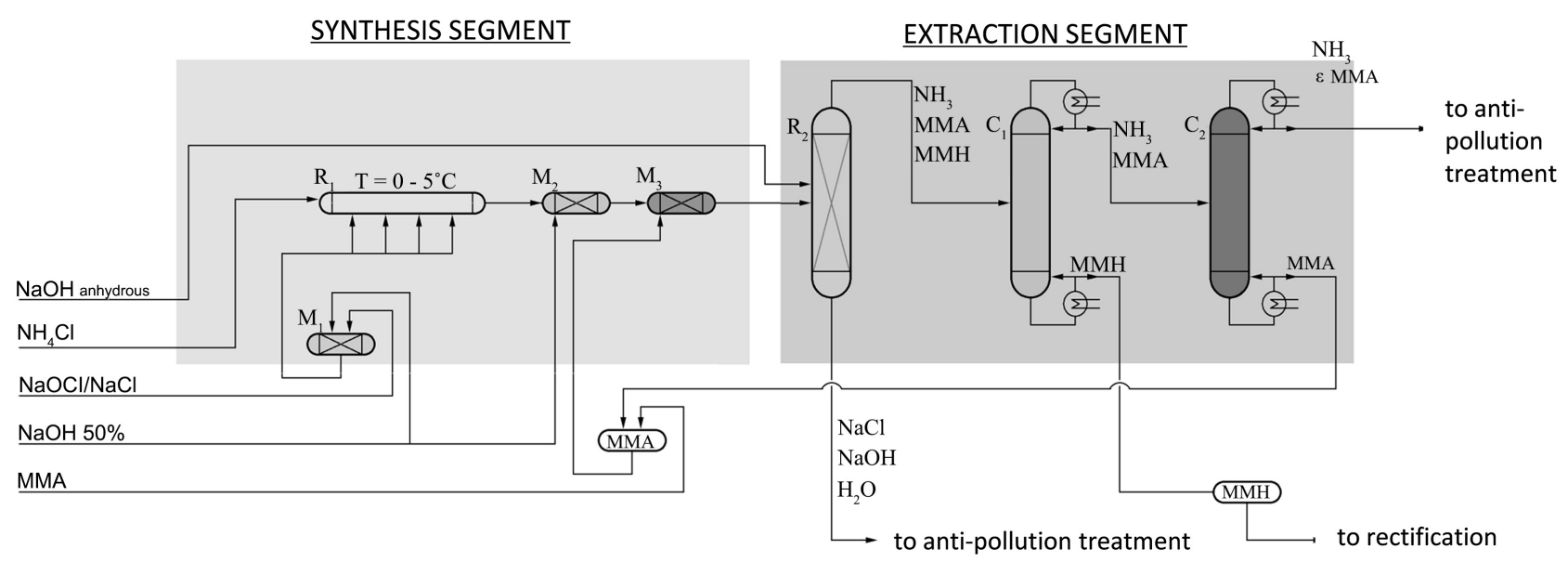

Figure 3. New process for the synthesis of $M M H . M_{1}, M_{2}, M_{3}$ : static mixers; $R_{1}$ : multi-stage injection microreactor; $R_{2}$ : demixing reactor; $\mathrm{C}_{1}, \mathrm{C}_{2}$ : separating columns (distillation).

\section{Conclusion}

In the end, the study of the main reactions that affect yield during the synthesis of MMH by the chloramine route led to the establishment of a global kinetic model for the synthesis of MMH. In order to validate the results of the calculation and to verify the absence of traces of hydrazine $\left(\mathrm{N}_{2} \mathrm{H}_{4}\right)$ in the synthesis solutions, a device for synthesis under pressure by direct injection of stoichiometric 
chloramine into the anhydrous MMA has been developed. The good agreement between experimental and calculated results made it possible to validate the kinetic model and to propose a new MMH synthesis process.

\section{Conflicts of Interest}

The authors declare no conflicts of interest regarding the publication of this paper.

\section{References}

[1] Le, D.M., Bougrine, A.J., Pasquet, V. and Delalu, H. (2019) A New Strategy for the Synthesis of Monomethylhydrazine Using the Raschig Process. 1. Study of the Stability of Monochloramine. Reaction Kinetics, Mechanisms and Catalysis, 127, 757773. https://doi.org/10.1007/s11144-019-01593-x

[2] Le, D.M., Bougrine, A.J., Duclos, O., Pasquet, V. and Delalu, H. (2020) A New Strategy for the Synthesis of Monomethylhydrazine Using the Raschig Process. 2: Continuous Synthesis of Stoichiometric Monochloramine Using the Microreactor Technology. Reaction Kinetics, Mechanisms and Catalysis, 130, 17-34. https://doi.org/10.1007/s11144-020-01761-4

[3] Reynolds, B.A. and Thomas, A.A. (1965) A Colorimetric Method for Determination of Hydrazine and Monomethylhydrazine in Blood. American Industrial Hygiene Association Journal, 26, 527-531. https://doi.org/10.1080/00028896509342767

[4] Ferriol, M., Abraham, R., Delalu, H. and Cohen-Adad, M.T.S. (1982) Kinetics of Monomethylhydrazine Formation from Monochloramine and Methylamine. Journal de Chimie Physique, 79, 725-728. https://doi.org/10.1051/jcp/1982790725

[5] Giudice, M. (1989) Preparation by the Raschig Process-Solid-Liquid Equilibrium of the $\mathrm{CH}_{3} \mathrm{NHNH}_{2}-\mathrm{H}_{2} \mathrm{O}$ System. Thesis at the University of Lyon, Lyon, 89-30.

[6] Ferriol, M., Gazet, J., Rizk-Ouaini, R. and Cohen-Adad, M.T.S. (1989) Chlorine Transfer from Chloramine to Amines in Aqueous Medium. 1. Reaction between Chloramine and Methylamine. Inorganic Chemistry, 28, 3808-3813.

https://doi.org/10.1021/ic00319a012

[7] Colton, E., Jones, M.M. and Audrieth, L.F. (1954) The Preparation of Hydrazine from Urea and T-Butyl Hypochlorite. Journal of the American Chemical Society, 76, 2572-2574. https://doi.org/10.1021/ja01638a080

[8] Yagil, G. and Anbar, M. (1962) The Kinetics of Hydrazine Formation from Chloramine and Ammonia. Journal of the American Chemical Society, 84, 1797-1803. https://doi.org/10.1021/ja00869a005

[9] Anbar, M. and Yagil, G. (1962) The Hydrolysis of Chloramine in Alkaline Solution. Journal of the American Chemical Society, 84, 1790-1796. https://doi.org/10.1021/ja00869a004

[10] Riley, R.F., Richter, E., Rotheram, M., Todd, N., Myers, L.S. and Nusbaum, R. (1954) The hypobromite and hypochloride oxidation of ammonium hydroxide, hydrazine and hydroxylamine. Journal of the American Chemical Society, 76, 3301-3303. https://doi.org/10.1021/ja01641a067

[11] Riley, K.F., Hobson, M.P. and Bence, S.J. (2006) Mathematical Methods for Physics and Engineering: A Comprehensive Guide. 3rd Edition. Cambridge University Press, Cambridge, UK. 